\title{
Research on Current Situation, Problems and Countermeasures of Interpretation Teaching of College English
}

\author{
Shaolin Wang \\ Jilin Business and Technology College, Jilin Province, Changchun, 130507
}

Keywords: Interpreting teaching, Interpreting course, College English

\begin{abstract}
Listening, speaking, reading, writing and translating are the five basic elements of English learning. Interpretation is an important part of translation. However, there are still many problems in the interpretation teaching of College English, which have a negative influence on the quality of teaching. Based on the problems analysis of interpretation teaching of College English, this paper puts forward some countermeasures, including cultivating interpreting teachers, enriching teaching models and reforming teaching content to provide some references for the relative researchers.
\end{abstract}

\section{Current Situation of Interpretation Teaching of College English}

Interpretation is a kind of language operation which combines the knowledge and skills of seeing, listening, speaking, writing and reading. The interpreter to source language for listening, understanding, memory, analysis, code conversion, and finally use the language to express. In the course of interpretation, the interpreter should have listening comprehension and information processing skills and language skills, including short-term memory, taking notes, translating figures, reading and translating, and other skills. Therefore, interpretation course is a specialized skill course. The basic skills of interpreting teaching basic theory, interpreting the background knowledge and interpreting training, to enable students to master the basic theory and thematic interpretation skills in consecutive interpreting, interpreting method, memory can learn oral outline, notes and public speaking skills, so that students can accurately and smoothly carry on Chinese English translation. Therefore, general higher education should be consistent in the direction of interpreting teaching, that is, the basic task of interpreting teaching is to cultivate interpreting skills. However, in interpreting teaching, we should also consider the specific circumstances of adult students, which are more complex in terms of the establishment of teaching objectives, the choice of teaching content and the setting of teaching content. In today's English , as the main tool of international communication status is constantly strengthened, college graduates with English interpretation ability has significant advantages in terms of employment, domestic various colleges and universities are open English interpretation courses, including some college, in addition to setting the interpretation for English majors to study courses in public elective courses provided in the form of interpreting learning opportunities. At present, the society of interpretation teaching of the research university for English majors interpreting course is necessary, at the same time to explore some problems of interpretation teaching, and put forward corresponding countermeasures.

\section{Problems of Interpretation Teaching of College English}

Deficient Interpretation Teachers. At present, there is a lack of high-level English interpretation teachers in Chinese universities. Teachers are lack of experience in interpreting, and even a lot of teachers after graduation directly to the teaching post, had never participate in interpreter training: provincial university this phenomenon is more prominent, due to the geographical location of these colleges is more remote, poor natural conditions, the economy is relatively backward, there is not enough economic conditions and ability to attract high-quality material professional translation talents, the overall level of the interpretation of teachers is far behind other colleges, and this phenomenon leads to a vicious spiral of education in the area, resulting in insufficient research on interpreting talents, to promote and deepen the curriculum reform. Therefore, the teaching quality is 
difficult to improve students' interpretatio and the level is not high, most of the students after graduation, because of the lack of practical skills, it is difficult to competent interpreter. Therefore, the lack of interpreting teachers in College English has become a bottleneck in the development of interpretation teaching. They do not have special interpretation skills training, and have no practical experience in business interpreting. Therefore, in the course of teaching, these teachers only through their own study of the relevant theoretical books, the use of traditional language teaching model, classroom teaching based, and teaching materials, as the center, to explain the book of theoretical knowledge. The practice of interpreting training has been translated into vocabulary, syntax and translation techniques. The face of this situation, the best solution is of course the interpretation teacher has practical experience of professional interpreters to teach business interpreting course. But it's hard for college. There is a practical reason why universities cannot introduce professional interpreters. The actual interpretation of work salary is much higher than the teachers, because of this point most interpreters to choose the teacher occupation, and college degree required to recruit teachers will practice light degree in College and universities outside the interpreter. Therefore, the lack of professional teachers directly leads to little effect on business interpreting teaching.

Single Teaching Mode. Learning is the process in which learners acquire knowledge through operational activities in a given environment. In this process, learners have to learn materials such as web information resources, multimedia courseware, videos, and so forth. English interpretation teaching should make full use of multimedia technology, language laboratories, audio-visual materials, television, campus network and other audio-visual aids and other teaching resources: however, the modern educational technology, many domestic universities for nationalities utilization rate is low, even some universities have not matched the language laboratory, interpreting the lack of basic equipment and multimedia teaching conditions basically, still remain the traditional interpretation teaching mode. Although some schools use multimedia technology, the students are still in a virtual environment. Either the teacher reads, or automatically plays, and does not see the voice of the speaker. The constant teaching of language laboratory cannot create a real atmosphere of interpersonal communication, lack of interpersonal interaction and language environment on the spot, and the effect of interpretation teaching is not satisfactory. Due to the lack of professional business interpretation, the current business interpreting course in Colleges and universities teaching most of the traditional language teaching mode, the teacher classroom teaching, mainly on vocabulary and grammar knowledge, supplemented by interpreting theory and translation skills, and students are seldom really interpreting practically In such a teaching mode, students cannot exert their subjective initiative, train comprehensive abilities of listening, speaking, reading, writing and translating, practice their interpreting skills, and exercise their own interpretation quality. Such a teaching model does not conform to the characteristics of the interpretation itself, and the students who teach it cannot open their oral interpretation tests, let alone enter the real interpretation field as an interpreter.

Backward Teaching Content. Interpretation requires interpreters to have good interpreting skills and background knowledge. However, the current interpretation teaching focuses on the teaching and training of interpreting skills, ignoring the importance of professional knowledge in interpreting and the practical nature of interpreting. The teaching content of interpretation should be divided into two parts, one is the teaching and training of interpreting skills, and the other is the practical training of business interpretation in two. With the growth of demand for business interpreting, a number of specialized business interpreting textbooks have appeared on the market, which are different from other interpreting textbooks. This is a good trend, but there are still some problems. First, the content of teaching materials is obsolete and the supporting resources are scarce; Second, it is too difficult to provide training materials for interpreters, especially for undergraduates in local universities. In the process of interpreting, the listening ability, note taking ability and comprehension ability are very high. Moreover, the lack of professional listening, listening, training and instant memory training in the entrance of higher vocational students leads to the obstruction of the interpreting process. The textbook is a necessary method to achieve the purpose of teaching. Teaching materials are the basis of teacher's class. Good teaching materials are the tools for teachers to have good lessons. Interpretation is a subject closely following the market. At present, China's market has many "interpreting 
textbooks", these materials are superior for each one has its own merits, and there are many, the authors have adopted the theme of training ranking, but still not get rid of the traditional teaching mode, translation theory and translation practice disjointed, language training, logic thinking training, some skills to explain, but is still in the stage of experience, it is difficult for students to draw inferences. Although many English textbook market, but close to the times, to meet the communication of interpreting textbooks is not much, only there are some textbooks and materials, old writting translation supporting backward shortcomings.

\section{Countermeasures of Interpretation Teaching of College English}

Cultivate Interpretation Teachers. It is suggested that teachers who teach interpretation courses should make corresponding demands in the professional direction, such as encouraging their own professional research directions and interpreting classes for interpreting teachers. The most important reason is that teachers are the professional learning of interpretation, is through professional and systematic training in teaching will be relatively more professional, also can more easily understand the students in the study of the problems in interpreting the professor teachers also need to constantly improve their level of business. Suggestions of interpretation teachers in addition to teaching work, can do some part-time interpreting in the society, in order to enrich their interpreting practice experience, because the interpretation itself only in practice in order to continuously improve. As a result, teachers can combine their own practical experience to teach. Overseas employment and skilled migration are also attractive. However, there is a higher demand for language skills, and with the skills they have learned, there will undoubtedly be more opportunities for their career paths to be provided with some interpreting skills. As English major teachers they must be capable of interpreting the interpreter's daily work, and classroom teaching experience to focus on in the current situation of minority college level, English interpretation of teachers is not high, take the training principle, and actively promote the construction of double type teachers' ocupation: the first is to strengthen the training of in-service teachers interpreting plan. The organization out of training, improve the existing teachers' level of interpretation; Second, it is the introduction of a high level of professional translators and teachers, so that they are served in the interpreting course teaching at the same time, who are responsible for the professional training of the existing Interpretation of teachers; Third, it is that the government should give policy support to personnel, especially in the areas of finance and personnel to be tilted to treatment. The interpreter to attract senior occupation colleges for Nationalities as an interpreter of teaching work, to create double interpretation of teachers.

Enrich Teaching Models. The intrinsic motivation of students' learning comes from the learning process of oral translation courses. They are interested in learning and have a sense of satisfaction and fulfillment through their learning. Interpretation class is boring training, but the teacher's teaching methods, content choices, etc., are very important to stimulate students' interest in learning. In interpreting teaching, teachers should pay attention to combining interpretation theory and skill knowledge with practical training, and arouse the initiative and enthusiasm of students. For example, you can simulate the ncluding the general assembly and the press conference interpretation, business negotiations, role play, group discussion, and speeches. In the curriculum, on the one hand, because the students in school during most of the time is to learn their own professional courses, the class is only open to a public elective, and the fact that elective class is limited, once a week for two hours, only in the classroom with limited training time; on the other hand, the number of elective classes class usually more than twenty people, so in one class the teacher cannot ensure that every student has the opportunity to practice; in addition, the location of the class and the corresponding hardware facilities may be limited, general professional interpreting training needs under certain conditions, such as with a corresponding voice equipment of the professional classroom training of listening and translation, while most universities may not have such a professional Shi. Teachers can give students a topic in advance to prepare students for a few minutes of speech, in which they can speak in their native language or in English, while his classmates act as interpreter. The teacher corrects or affirms after translation and comments. 
Reform Teaching Content. In order to set up an elective course for interpreting, most of the textbooks in the field of interpreting are currently available. Among them, there are textbooks written for the purpose of obtaining the qualifications for interpreting in the society and textbooks for interpreting majors in colleges and universities. These materials are more specialized, and involve large subjects such as politics, economy and culture. The above two categories of teaching materials in the content and the degree of difficulty, are more suitable for social English level to a high level and are willing to obtain qualification for interpreting target learners, or college students. However, the language degree and application ability is relatively weak in major college students, taking into account the needs of their occupation, for the students' language level is not suitable for this kind of textbook, written in interpreting textbooks on language accumulation and language ability, such as the commonly used formula gives a lot situational interpretation in the content of the memory for the students in learning, in practice they can also be used as reference materials. In practice, on the other hand, for oral class can be increased appropriately, the common elective course once a week to two times a week, to ensure that students have more classroom training and guidance; furthermore, the number of students in the classroom should be controlled, generally through prescreening according to the language level after the number can be controlled small class teaching in about more than ten people; in addition, the university in the school condition with interpreting training room for the practice of simulation exercises, of course there is the use of existing school facilities for the university students of English courses. And the professional training room proposal is also open in interpreting elective courses for students to use.

\section{Conclusion}

To sum up, there are still many problems in the teaching of college English interpretation. In order to solve these problems, teachers and colleges need to cooperate with each other. Only by adding excellent interpretation teachers and reforming the content and mode of teaching can make us truly deliver more excellent interpreters to the society.

\section{References}

[1] Xu Han, An Empirical Study on English Skill-focused Approach to Interpreting Teaching in Undergraduate Course [J]. Education Research Monthly, 2013(11): 98-102.

[2] You Ting, A Study on the Internet-based Interactive Teaching Mode in the Undergraduate English-Chinese Interpreting Course [J]. Overseas English, 2016(2): 80-81.

[3] Su Hongquan, Exploration on Interpreting Teaching for Non -English Majors of Higher Vocational Colleges: The Necessity, Problems and Countermeasures [J]. The Science Education Article Collects, 2015(4): 182-184.

[4] Li Juan, Research on Business Interpreting Teaching in Local Universities and Colleges [J]. Overseas English, 2015(24): 299-300. 